\title{
Anestesi Epidural Thorakal Pada Tumor Phyllodes
}

\section{Epidural Thoracal Anesthesia in Phyllodes Tumour Excision}

Yudi Hadinata*, Djudjuk Rahmad Basuki*, Hari Bagianto*

*Bagian Anestesiologi dan Terapi Intensif FK Unibraw/ RSUD dr. Saiful Anwar, Malang

\begin{abstract}
Background: The development of neuroaxial technique in anesthesia has been contribute in providing good anesthesia and analgesia for surgery procedure and postoperative pain management. Epidural anesthesia has been one of the versatile technique widely used in anesthesia. This anesthesia technique can be performed regarding the operation site from the cervical, thoracal, lumbar or caudal region.

Case: We report a case of anesthesia technique using thoracal epidural inserted at the site of intervertebrae thoracal space 7-8 to accommodate mastectomy surgery in female patient ASA II with phyllodes mammary tumor.
\end{abstract}

Keyword: thoracic epidural anesthesia, mastectomy

\section{ABSTRAK}

Latar Belakang: Perkembangan teknik anestesi neuroaksial telah memberikan kontribusi yang bermanfaat untuk prosedur anestesi dan analgesia, baik selama prosedur operasi maupun tatalaksana nyeri pasca operasi. Anestesi epidural merupakan salah satu teknik anestesi yang telah digunakan secara umum. Teknik anestesi tersebut bisa dilakukan dengan melihat dermatom area operasi yang dipersarafi sesuai regio servikal, torakal, lumbal maupun caudal.

Kasus: Pada kasus ini kami melaporkan penggunaan anestesi epidural mid-thorakal dengan insersi pada ruang intervertebra torakal 7-8 untuk mengakomodasi prosedur operasi mastektomy pasien wanita ASA II dengan tumor payudara phyllodes kiri.

Kata kunci: anestesi epidural torakal, mastektomi

\section{PENDAHULUAN}

Penggunaan teknik epidural anestesi dan analgesi torakal mengalami peningkatan seiring dengan perkembangan operasi abdomen, torak dan kardiovaskuler. Tujuan dari penggunaan blok epidural torakal tidak semata untuk menghalangi rangsangan nyeri melalui serabut saraf afferen luka operasi tetapi juga simpatektomy yang selektif pada daerah torakal. Dampak penurunan rasa nyeri dan simpatektomi yang terjadi akan mengurangi stress paska operasi sebagai proteksi terhadap jantung dan pernafasan dengan memudahkan pasien untuk bernafas dalam, batuk yang adekuat, ekstubasi dini dan mobilisasi awal serta menjaga fungsi pencernaan sehingga mempengaruhi penyembuhan paska operasi yang lebih baik. ${ }^{1}$

\section{KASUS}

Seorang wanita berusia 52 tahun, berat badan $60 \mathrm{~kg}$ didiagnosa tumor phyllodes sinistra dilakukan 
mastektomy sederhana dengan anestesi epidural midtorakal. Dari anamnesa perioperatif tidak didapatkan riwayat alergi obat atau makanan. Tidak didapatkan riwayat sakit seperti asma, diabetes mellitus, ataupun konsumsi antikoagulan. Diketahui pasien selama ini memiliki hipertensi grade 1 dan mendapatkan captopril 3 x $12.5 \mathrm{mg}$. Premedikasi diberikan ranitidine $50 \mathrm{mg}$ dan metoclopramide $10 \mathrm{mg}$ intravena 1 jam sebelum tindakan anestesi dan operasi.

Pemeriksaan fisik secara umum didapatkan data nafas spontan, RR $14 \mathrm{x} /$ $\mathrm{m}$, saturasi udara ruangan $98 \%$, jalan nafas normal, buka mulut $>2$ jari, jarak thyromental $>3$ jari, Mallampati II, fleksi ekstensi leher normal, suara nafas vesikuler kedua paru, tidak didapatkan ronkhi maupun wheezing.

Akral hangat, kering, merah, CRT $<2$ detik, Nadi $84 x / \mathrm{m}$, TD 130/70 $\mathrm{mmHg}$, Suara jantung I dan II normal, tidak ada murmur ataupun gallop. Tidak didapatkan anemia konjungtiva. Compos mentis, tidak didapatkan defisit neurologis. Motoris baik, Sensoris normal. Miksi spontan, normal, warna kuning jernih. Bising usus $(+)$ normal. Tidak didapatkan kelainan tulang ekstremitas maupun vertebra, evaluasi intervertreba space 7-8 mudah diidentifikasi.

Status lokalis massa tumor phyllodes payudara kiri dengan ukuran 30x35×20 $\mathrm{cm}$, konsistensi padat, terdapat tanda radang, eritrema serta nyeri tekan (gambar 1).

Data tambahan rontgen thorak PA, EKG, laboratorium darah lengkap, faal hemostasis, elektrolit, fungsi hati, fungsi ginjal, dan gula darah sewaktu menunjukkan data normal. Dari data tersebut pasien diklasifikasikan status fisik ASA 2 dengan hipertensi. Pasien selanjutnya mendapatkan penjelasan dan menandatangani persetujuan mengenai prosedur anestesi dan bedah yang akan dikerjakan.

Persiapan pembiusan umum dan obat emergensi dipersiapkan sebelum prosedur anestesi dimulai. Pasien mendapatkan injeksi midazolam $2.5 \mathrm{mg}$ dan petidhine $50 \mathrm{mg}$ intramuskuler 30 menit sebelum prosedur anestesi di ruang premedikasi. Pasien diposisikan duduk dan diidentifikasi celah intervertebra torakal 7-8 sesuai tepi inferior scapula. Dilakukan tindakan asepsis dan antisepsis, kemudian jarum epidural disuntikkan dengan cara paramedian teknik loss of resistance (LOR) menggunakan cairan NS $0.9 \%$ didapatkan jarak LOR sedalam $4 \mathrm{~cm}$. Kateter epidural dimasukkan sepanjang $8 \mathrm{~cm}$ pada tepi kulit dan diberikan test dose dengan lidocaine $1 \% 30 \mathrm{mg}+$ Epinephrine 1:200.000 (volume $3 \mathrm{cc}$ ). Evaluasi setelahnya tidak menunjukkan perubahan nadi, tekanan darah, tinnitus, oral numbness, maupun gelombang EKG serta blok motorik. Selanjutnya diberikan dosis epidural menggunakan bupivacaine $0.5 \% 50 \mathrm{mg}$ (volume total $10 \mathrm{cc}$ ) dengan cara inkrimental. Blok sensoris tercapai pada ketinggian $\mathrm{T}-1$ dengan batas bawah Th-8 pada menit ke 30 menggunakan evaluasi pinprick test dan kapas alkohol, Evaluasi otot pernafasan dilakukan dengan menanyakan kepada pasien apakah ada keluhan dalam usaha ventilasi dan melihat pola nafas pasien. Setelah anestesi dinyatakan berjalan, maka operasi bisa dimulai. Operasi berjalan lancar selama 210 menit, dan pada 30 menit sebelum operasi berakhir dilakukan pemberian dosis bupivacaine $(0.125 \%+$ morfin $2 \mathrm{mg})$ volume $10 \mathrm{cc}$ untuk analgesia paska operasi. 

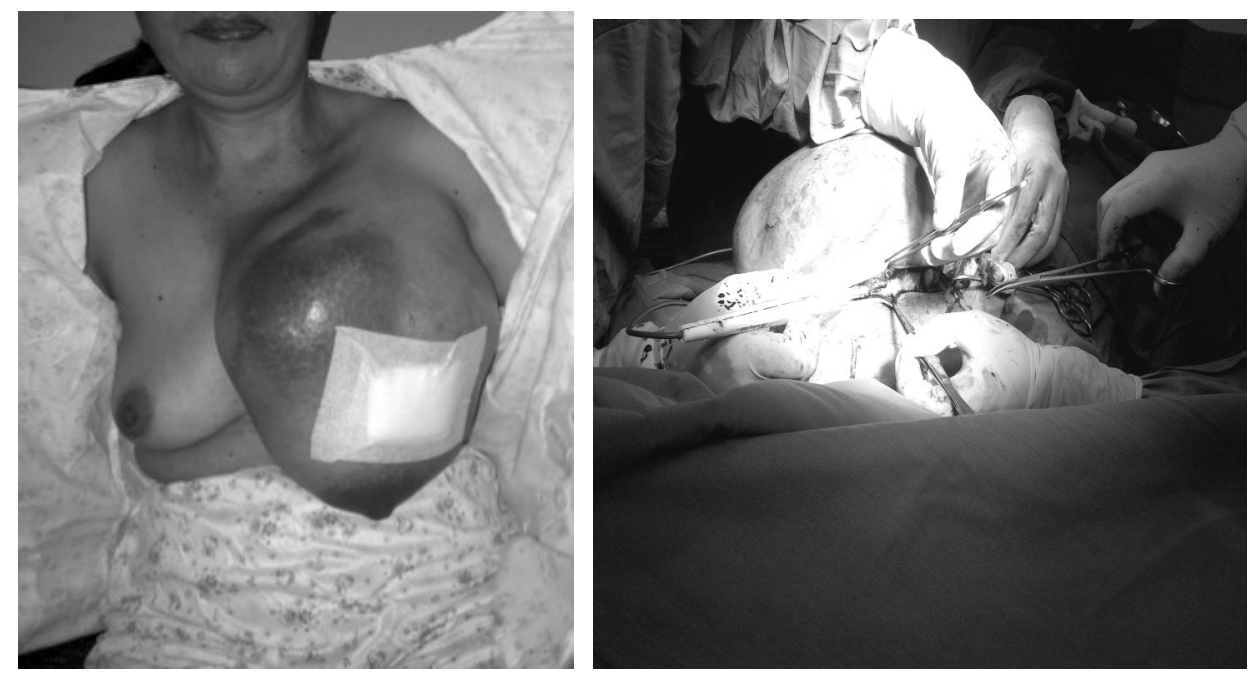

Gambar 1. Tumor phyllodes kiri

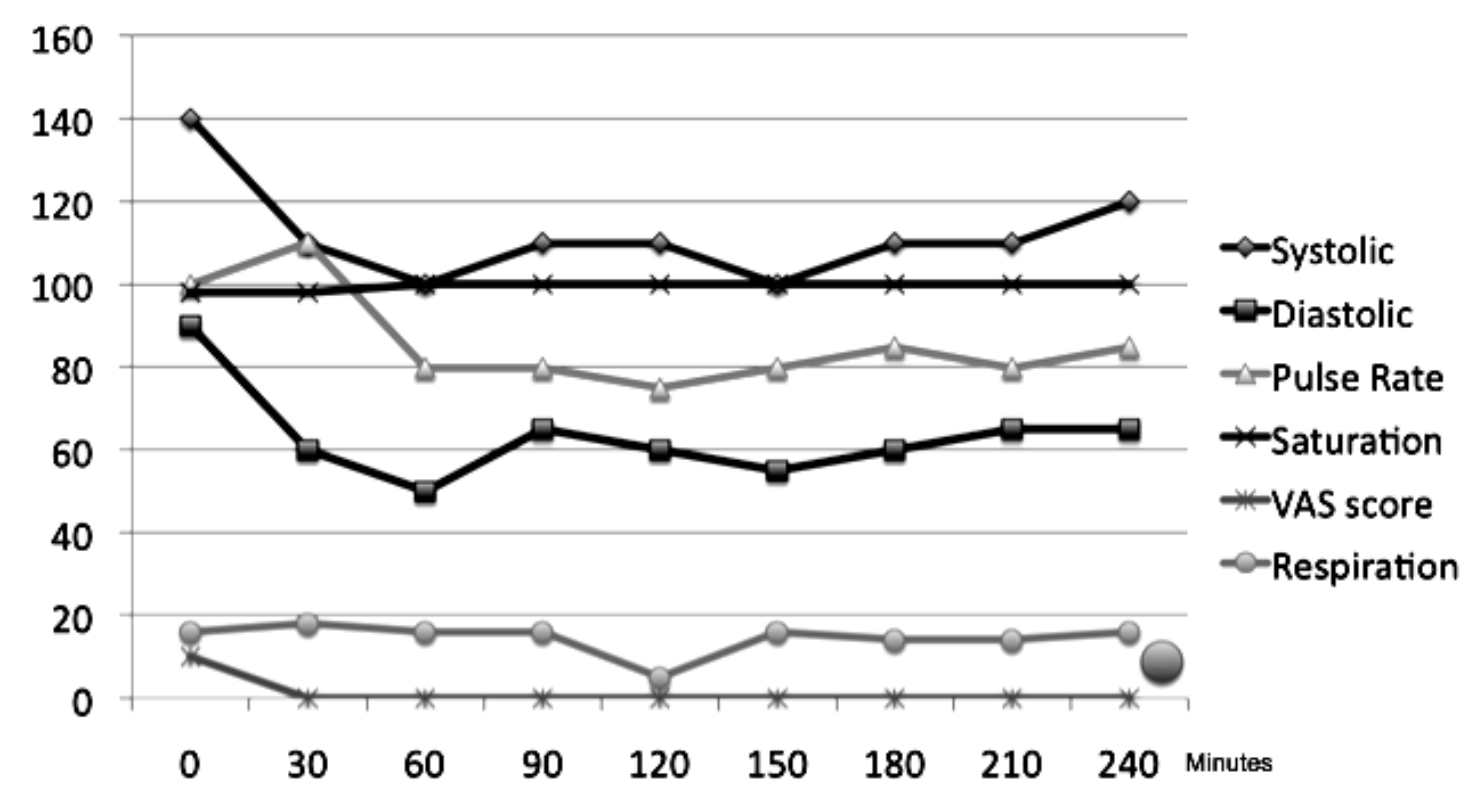

Gambar 2. Grafik Tanda vital durante operasi 
Parameter hemodinamik dan respirasi selama prosedur operasi relatif stabil dan tidak membutuhkan obat vasopresor maupun inotropik dan analgesia lain selama prosedur operasi, ataupun bantuan ventilasi (gambar 2).

Paska operasi diberikan regimen analgesik bupivacaine $(0.125 \%+$ morfin $2 \mathrm{mg}$ ) volume $10 \mathrm{cc}$. Observasi terhadap keluhan nyeri paska operasi selama 4 hari pemasangan epidural memiliki rentang skor VAS 0-1 dan tidak terdapat gangguan respirasi maupun hemodinamik. Pasien juga tidak mengeluhkan pruritus ataupun mual muntah karena morfin dan tidak memerlukan tambahan analgesik lain. Mobilisasi dini dapat segera dilakukan saat pasien pindah ke ruang rawat (Gambar 3).

\section{PEMBAHASAN}

Phyllodes tumor pertama kali dilaporkan oleh Johannes Muller pada tahun 1838 dengan istilah cystosarcoma phyllodes. Tumor ini merupakan bentuk neoplasma fibroepitelial dengan angka kejadian 0.3 $-1 \%$ dari kasus tumor payudara dan memiliki potensi terjadi rekurensi sebesar $20 \%$. Tumor ini diklasifikasikan berdasarkan gambaran histopatologisnya menjadi tipe benign, borderline, dan malignant. ${ }^{2}$ Terapi pada kasus ini adalah tindakan operasi berupa eksisi biopsi, eksisi luas atau mastectomy dan dilanjutkan dengan tindakan kemoterapi atau radioterapi b e r d a s a k a n g a b a r a n histopatologinya.,

Operasi tumor payudara dapat dikerjakan melalui beberapa pilihan teknik anestesi seperti anestesi lokal, blok interkostalis, blok paravertebra, blok epidural torakal, pembiusan umum ataupun kombinasi pembiusan umum dan regional. ${ }^{5}$ Anestesi epidural torakal
(TEA) pada kasus tumor phyllodes ini menjadi pilihan karena massa tumor yang membutuhkan blok area payudara hingga melewati midline sternum, serta tatalaksana nyeri paska operasi yang lebih efektif.

Teknik penusukan jarum untuk TEA ada dua cara yaitu median dan paramedian. Teknik median menjadi pilihan pada torakal tinggi (T1-T3) dan torakal rendah (T10-T12), sementara cara paramedian lebih dipilih pada lokasi midtorakal (T4T9) karena sudut prosesus spinosus yang lebih prominen pada regio midtorakal. Pada teknik paramedian, jarum epidural dimasukkan kira-kira $2 \mathrm{~cm}$ lateral dan 2 $\mathrm{cm}$ inferior dari prosesus spinosus level torakal yang dipilih dengan sudut $45^{\circ}$ terhadap kulit dan arahnya medial kirakira $15-20^{0}$ terhadap midline (gambar 4). 6

Ketinggian blok yang diharapkan disesuaikan dengan dermatome manipulasi operasi yang akan dikerjakan

Ujung kateter diharapkan berada pada titik tengah luas lapangan operasi yang akan dikerjakan. Hal lain yang berpengaruh pada ketinggian blok adalah jumlah volume obat yang dimasukkan, dimana pada level torakal dapat terisi 0.75-1 cc/segmen torakal. ${ }^{7}$ Pada kasus ini blok sensoris diidentifikasi dengan tes pinprick dan kapas alkohol seluas area T1-T8.

Jenis obat anestesi lokal yang digunakan akan berpengaruh terhadap onset dan durasi blok yang terjadi, sementara konsentrasi obat anestesi lokal akan berpengaruh pada jenis blok yang terjadi

Penambahan ajuvan lain seperti opioid, alfa-2 agonis dan epinephrine dapat memperpanjang durasi blok serta modulasi efek analgesiknya. Akan tetapi observasi efek samping masing-masing 


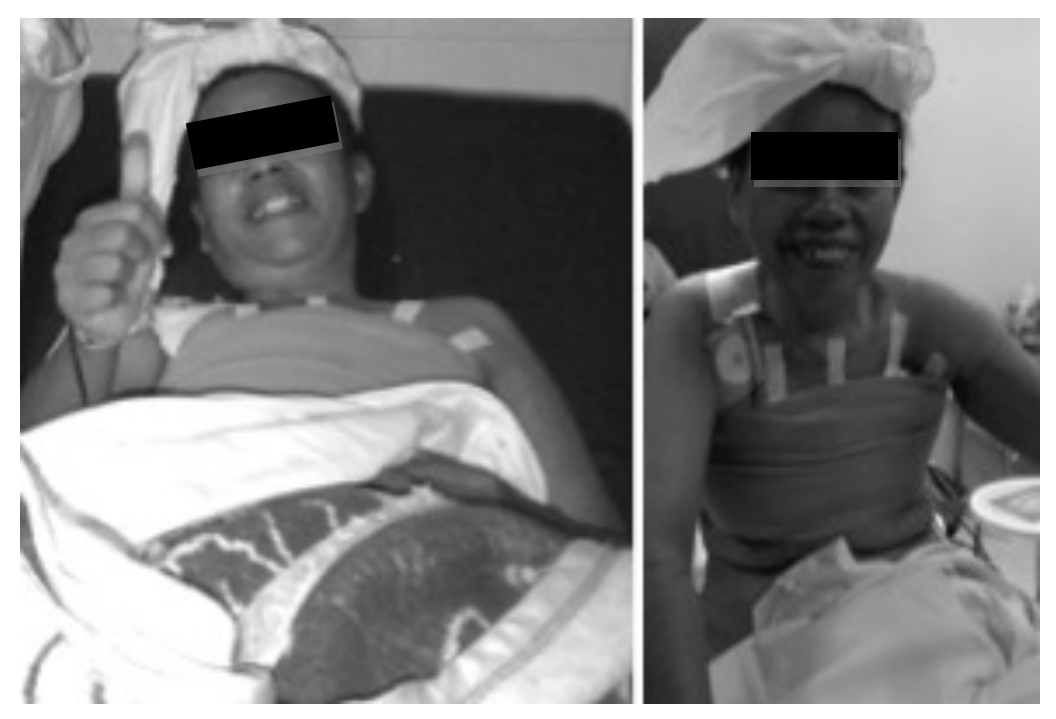

Gambar 3. Kondisi pasca operasi

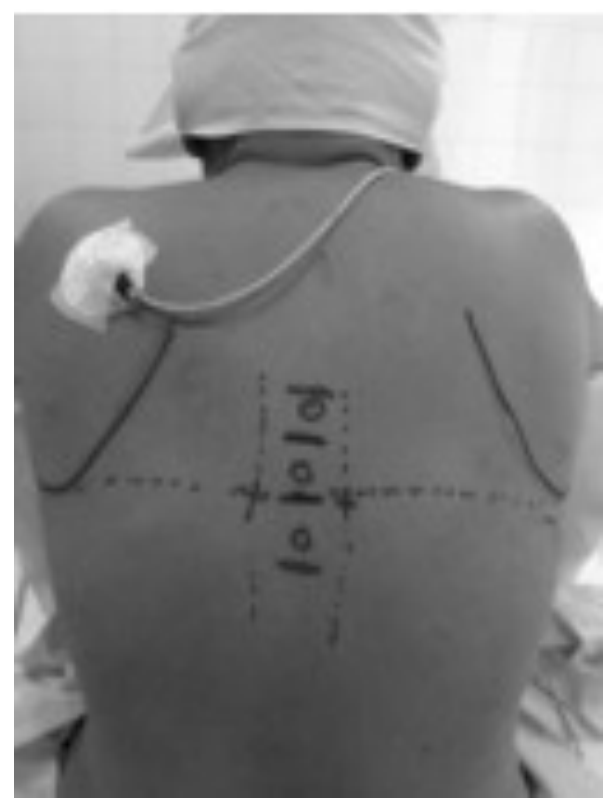

Gambar 4. Pendekatan paramedian TEA 
ajuvan perlu diwaspadai. ${ }^{8}$

Paska anestesi terjadi penurunan hemodinamik dari tekanan darah awal 120-140 / 70-90 mmHg menjadi 100120 / 60-70 mmHg, akan tetapi obat vasopresor tidak pernah diberikan. Cairan perioperatif diberikan ringer laktat (RL) sesuai kebutuhan maintenance, dan co-loading cairan RL $10 \mathrm{cc} / \mathrm{KgBB}$ diberikan sebelum tindakan anestesi.

Persiapan tatalaksana cairan perioperatif yang cukup diperlukan untuk mengurangi resiko hipotensi selama prosedur TEA. Hipotensi dapat terjadi karena selektif kardiodepresan atau vasodilatasi tonus arteri dan vena. Tonus vaskuler perifer dipengaruhi secara langsung oleh stimulasi simpatis pada reseptor adrenergik a dan $b$, serta secara tidak langsung oleh norepinephrine yang dilepaskan medulla adrenal. Blok simpatis T5-L1 dapat menurunkan norepinephrine dari renal dan mempengaruhi sistem renin angiotensin serta vasopresin. ${ }^{9,10}$ Penurunan renin akan menyebabkan peningkatan vasopressin endogen untuk mengkompensasi penurunan hemodinamik. ${ }^{11,12}$ Penggunaan obat antihipertensi captopril juga harus diwaspadai sebagai faktor resiko terjadinya hipotensi paska TEA.

Epidural torakal tinggi dapat secara potensial memblok serabut saraf afferen dan efferent jantung pada inervasi T1T5. ${ }^{13}$ Dengan TEA, terdapat pengurangan frekuensi jantung yang minimal pada pasien sehat dan yang menjalani operasi. ${ }^{14,15}$ Pada operasi arteri karotid, penggunaan TEA dapat menurunkan reaktivitas dari baroreflek akan tetapi blok total terhadap reflek ini tidak pernah didapatkan. ${ }^{16}$ TEA dapat menyebabkan perlambatan denyut jantung dan memperpanjang fase refrakter dari konduksi nodus $\mathrm{AV}$, hal tersebut dapat mengurangi resiko disritmia ventrikel selama pembedahan jantung atau bypass kardiopulmoner, akan tetapi resiko kejadian disritmia atrium tidak berubah. ${ }^{17,18}$

Curah jantung dapat menurun dengan TEA, walaupun evaluasi kontraksi miokardium dengan transthoracic echocardiography dilaporkan tidak berpengaruh terhadap pengisian serta ejeksi ventrikel kiri pada relawan sehat dan pasien dengan resiko iskemia. ${ }^{19,20}$

Arteri koroner jantung dipersarafi oleh serabut saraf simpatis adrenergik. Stimulasi rangsang simpatis dapat menyebabkan vasokontriksi koroner, sementara blok tinggi TEA dapat mengurangi vasokontriksi yang terjadi. ${ }^{21,22,23}$ Pada pasien dengan penyakit koroner berat dan angina tidak stabil, TEA tinggi dapat mengurangi nyeri angina dengan vasodilatasi koroner dan menurunkan kebutuhan konsumsi oksigen dengan menurunkan tekanan darah sistolik, frekuensi denyut jantung, tekanan darah arteri pulmoner dan pulmonary capillary wedge pressure. ${ }^{24}$

Mekanisme komplikasi paska operasi pada sistem pernafasan bersifat multifaktorial oleh karena nyeri operasi, mobilisasi yang kurang, disfungsi otot diafragma, interkostalis, dan otot abdomen. Infeksi pneumonia dan atelektasis merupakan komplikasi yang dapat terjadi akibat prolonged intubasi dan kemampuan batuk yang kurang. ${ }^{25}$ Penggunaan epidural torakal dapat memberikan manajemen nyeri yang baik sehingga pasien merasa nyaman untuk bernafas dalam, batuk dan mobilisasi dini. ${ }^{6}$

Pada kasus ini pasien tidak mengeluhkan perubahan nafas yang membuat pasien merasa sesak atau nafas bertambah berat. 
Walaupun observasi selama operasi terhadap pola pernafasan tidak terdapat perubahan dari jumlah frekuensi nafas, saturasi atau penggunaan otot bantu pernafasan lain, akan tetapi resiko untuk terjadinya gangguan aktivitas otot pernafasan dapat terjadi karena TEA dapat menyebabkan blokade serabut saraf intercostalis. Tes fungsi paru dapat menilai hal tersebut.

Pada pasien TEA, pengukuran aktivitas elektrik pada muskulus intercostalis menunjukkan penurunan, akan tetapi otot lain seperti scalenus tidak menunjukkan peningkatan aktivitas listrik yang menandakan bahwa pada pasien dengan TEA dapat melakukan ventilasi dengan adekuat selama fungsi diafragma tidak terganggu. ${ }^{26}$ Hal ini disebabkan otot diafragma berperan pada $75 \%$ dari fungsi pernafasan dan dipersarafi oleh nervus phrenicus (C3C5). ${ }^{8}$

TEA dapat menyebabkan penurunan kapasitas inspirasi sebesar 11\%, kapasitas vital 13\% (VC), kapasitas total paru 9\% (TLC), kapasitas residu paru 6\% (FRC), FEV1 dan FVC sebesar $12 \% .^{27}$ Hal serupa juga diutarakan oleh Sundberg pada blok dermatom $\mathrm{T} 1$ - T5 dapat menurunkan VC sebesar 5.6\% dan FEV1 sebesar 4.9\% tanpa disertai keluhan dispneu atau kesulitan bernafas. ${ }^{28}$

Tenling et al. menemukan hal yang sama pada pasca operasi pasien operasi jantung terjadi penurunan $\mathrm{VC}$ dan FEV1 sebesar $10 \%$ dari nilai basal, akan tetapi pasien-pasien dengan TEA mampu melakukan tes fungsi paru 1 jam paska ekstubasi dibandingkan dengan pasien yang menerima opioid sistemik. Dengan mempertimbangkan bahwa FEV1 mencerminkan kemampuan pasien untuk melakukan batuk, hal tersebut menunjukkan FEV1 memiliki kepentingan yang lebih dibandingkan tes fungsi paru yang lain. $^{25}$

Aplikasi TEA pada pasien PPOK berat dengan penggunaan ekstensif otot diafragma dan interkostalis menunjukkan penurunan VC dan FEV1. Pada percoban oleh Groeben dengan blok pada dermatom C5-T8 menggunakan bupivakain epidural $0.75 \%$ volume $6-8 \mathrm{cc}$, terjadi penurunan VC dan FEV1 serta hemodinamik pasien, akan tetapi analisa gas darah tidak terganggu dan rasio FEV1/FVC atau FRC tetap. Hal serupa diungkapkan Gruber dengan TEA pada pasien PPOK menggunakan bupivakain $0.25 \%$ volume $10-12$ cc dimana pola nafas, kekuatan otot nafas inspirasi, pertukaran gas dan ventilasi mekanik tidak terganggu. ${ }^{29,30}$ Walaupun terjadi penurunan FEV1, VC, dan rasio FEV1/ VC pada TEA pasien operasi payudara dengan premorbid PPOK yang dilaporkan Groeben, akan tetapi tidak terdapat perbedaan yang signifikan antara obat bupivakain $0.75 \%$ dan ropivakain $0.75 \%$ yang digunakan. ${ }^{30}$

\section{RINGKASAN}

Operasi payudara yang tidak melibatkan manipulasi intratorakal seperti pada operasi mastektomi tumor phyllodes ini, bisa dilakukan dengan tindakan anestesi epidural torakal murni. Pemilihan teknik TEA harus didasari pada kondisi premorbid pasien dengan kewaspadaan terhadap kemungkinan depresi sistem respirasi dan kardiovaskular. Dengan menggunakan teknik TEA ini maka nyeri paska operasi dapat teratasi dengan baik, terjadi penurunan insiden mual dan muntah paska operasi, durasi perawatan paska operasi yang lebih singkat, resiko ileus yang lebih singkat dan penurunan komplikasi pernafasan. 
Walaupun penggunaan bupivacaine $0.5 \%$ pada laporan kasus ini tidak terdapat gangguan fungsi pernafasan yang dikeluhkan oleh pasien, akan tetapi bila memungkinkan maka pemilihan obat anestesi lokal untuk tindakan epidural sebaiknya dipilih yang memiliki resiko blok motorik lebih rendah, dalam hal ini ropivacaine, atau levobupivacaine dapat menjadi pilihan. Hal yang menjadi pertimbangan penggunaan bupivacaine $0.5 \%$ pada kasus ini adalah ketersediaan agen anestesi epidural dan teknik inkrimental yang digunakan dengan harapan untuk mencapai ketinggian blok tindakan operasi dengan dosis yang seminimal mungkin. Depresi nafas yang terjadi harus diantisipasi dengan kesiapan tindakan manajemen jalan nafas dan persiapan anestesi umum.

Penurunan hemodinamik yang terjadi pada kasus ini dapat dikompensasi dengan co-loading cairan dan tidak memerlukan obat vasopresor ataupun inotropik. Status hidrasi pasien menjadi perhatian sebelum tindakan anestesi dan selama durante operasi untuk menurunkan resiko hipotensi karena simpatektomy yang menyebabkan relatif hipovolemik. Persiapan obat vasokonstriktor seperti phenylephrine, efedrin atau norepinephrine dapat menjadi pilihan. Sementara gangguan intropik dapat dikompensasi dengan penggunaan dopamine ataupun dobutamine bila diperlukan.

\section{DAFTAR PUSTAKA}

1. McLeod GA. Thoracic epidural anaesthesia and analgesia. Critical care \& pain. 2004; 4 (1): 6-9.

2. Tan. Phyllodes Tumor Of The Breast. American Jurnal of Clinical Pathology. 2005; 23: 529-40.
3. Verslegers. Massive Infarction Of a Recurrent Phyllodes Tumor Of The Breast: MRI Findings. JBR-BTR. 2004. 87:21-22.

4. Altaf FJ, Daffa N. Phyllodes Tumor. Bahrain Medical Bulletin. 2004. 26(3): 1-8.

5. Cousins, MJ. Neural Blockade in Clinical Anesthesia and Pain Medicine $4^{\text {th }}$ ed. China. Lippincot Williams \& Wilkins. 2009. 11: 241-75.

6. Wong, Cynthia A. Spinal and Epidural Anesthesia. The McGraw-Hill Companies. United State of America. 2007. 9: 221-26.

7. Dunn, Peter F. Clinical Anesthesia Procedures of the Massachusets General Hospital $7^{\text {th }}$ edition. Boston: Lippincot Williams \& Wilkins: 2007; 16:248-72.

8. Morgan. Clinical anesthesiology $4^{\text {th }}$ ed. US: Lange: 2007; 16: 248-72.

9. Kaneko Y. Renin release during acute reduction of arterial pressure in normotensive subjects and patients with renovascular hypertension. J Clin Invest. 1967; 46: 705-16.

10. Kirchheim H. Sympathetic modulation of renal hemodynamis, renin release and sodium excretion. Klin Wochenschr 1989; 67: 858-64.

11. Hopf HB. Sympathetic neural blockade by thoracic epidural anesthesia suppresses renin release in response to arterial hypotension. Anesthesiology 1994; 80:992-99.

12. Peters J. Sympathetic blockade by epidural anesthesia attenuates the cardiovascular response to severe hypoxemia. Anesthesiology 1990; 72:134-144.

13. Goodson AR, Leibold JM, Guteterman DD. Inhibition of nitric oxide synthesis augments centrally induced sympathetic coronary vasoconstriction in cats. Am J Physiol 1994; 267:1272-8

14. Wattwil M. Circulatory changes during high thoracic epidural anesthesia-influence of symphatetic block and systemic effect of the local anaesthetic. Acta Anaesthesiol scand 1985; 29:849-55.

15. Loick HM. High thoracic epidural anesthesia, but not clonidine, attenuates the perioperative stress response via sympatholysis and reduces the release of troponin $\mathrm{T}$ in patients undergoing coronary artery bypass grafting. Anesth Analg 1999; 88:701-9.

16. Bonnet F, Szekely B, Abhay K, et al. Baroreceptor control after cervical epidural anesthesia in patients undergoing carotid artery surgery. J Cardiothorac Anesth 1989; $3: 418-24$. 
17. Scott NB. A prospective randomized study of the potential benefits of thoracic anesthesia and analgesia in patients undergoing coronary artery bypass grafting. Anesth Analg 2001; 93:528-35.

18. Liu SS, Block BM, Wu CL. Effects of perioperative central neuraxial analgesia on outcome after coronary artery bypass surgery: a meta analysis. Anesthesiology 2004; 101:153-61.

19. Niimi Y. Echocardiographic evaluation of global left ventricular function during high thoraci epidural anesthesia. J Clin Anesth 1997; 9:118-24.

20. Saada M. Effect of thoracic epidural anesthesia combined with general anesthesia on segmental wall motion assessed by transesophageal echocardiography. Anesth Analg 1992; 75:329-35.

21. Buffington $\mathrm{CW}$, Feigl EO. Adrenergic coronary vasoconstriction in the presence of coronay stenosis in dog. Circ Res 1981; 48:416-23.

22. Brown BG. Response of normal and diseased epicardial coronary arteries to vasoactive drugs: quantitative arteriographic studies. Am J Cardiol 1985; 56:23-29.

23. Mudge GH Jr, Grossman W, Mills RM Jr, Lesch M, Braunwald E. Reflex increase in coronary vascular resistance. N Engl J Med 1976; 295:1333-7.
24. Lagunilla J. High thoracic epidural blockade increases myocardial oxygen availability in coronary surgery patients. Acta anaesthesiol Scand 2006; 50:780-6.

25. Tenling A. Thoracic epidural analgesia as an adjunct to gengeral enaesthesia for cardiac surgery. Effects on pulmonary mechanics. Act Anaesthesiol Scand 2000; 44:1071-6.

26. MacCarthy GS. The effect of thoracic extradural analgesia on pulmonary gas distribution, functional residual capacity and airway closure. Br J Anaesth 1976; 48:243-8.

27. Takasaki M, Takahashi T. respiratory function during cervical and thoracic extradural analgesia in patients with normal lungs. Br J Anaesth 1980; 52:1271-6.

28. Sundberg A, Wattmil M, Arvill A. Respiratory effect of high thoracic epidural anaesthesia. Acta Anaesthesiol Scand 1986; 30: $215-17$

29. Gruber EM. The effect of thoracic epidural analgesia with bupivacaine $0.25 \%$ on ventilatory mechanics in patients with severe chronic obstructive pulmonary disease. Anesth Analg 2001; 92:1015-9.

30. Groeben H. Lung function under high thoracic segmental epidural anesthesia with ropivacaine or bupivacaine in patients with severe obstructive pulmonary disease undergoing breast surgery. Anesthesiology 2002; 96:536-41. 